\title{
False Beliefs About Asylum Seekers to Australia: The Role of Confidence in Such Beliefs, Prejudice, and the Third Person Effect
}

\author{
Anne Pedersen ${ }^{1,2}$ and Lisa K. Hartley ${ }^{1}$ \\ ${ }^{1}$ Curtin University, Perth, Western Australia, Australia \\ ${ }^{2}$ Murdoch University, Perth, Western Australia, Australia
}

\begin{abstract}
$\mathrm{T}$ here has been much controversy about the treatment of asylum seekers in Australia in recent years, with the Australian Government continuing to enforce a very hard-line stance on asylum seekers who arrive to Australia by boat. The present study examined attitudes towards asylum seekers using 164 Australian community members during June 2015 by way of questionnaire. Our primary research question involved how five variables predicted false beliefs about asylum seekers. Specifically, we measured prejudice, the third-person effect, and confidence in the answers given to false beliefs about asylum seekers. Regression results indicated that the main predictors of false beliefs were right-wing political orientation, prejudice, confidence in espousing false beliefs, and the third-person effect (politicians). Furthermore, most of our community participants accepted a large number of false beliefs as being true, with approximately two-thirds of our participants scoring above the midpoint. This reflects similar findings over the last decade or so. Our results indicate that, if one believes in bottom-up change, a more nuanced approach needs to be undertaken with community anti-prejudice interventions.
\end{abstract}

Keywords: asylum seekers, refugees, false beliefs, confidence, prejudice, third-person effect

There has been much controversy about the treatment of asylum seekers in Australia in recent years, with the Australian Government continuing to enforce a very hardline stance on asylum seekers who arrive to Australia by boat. While community sentiment is mixed, with some Australians feeling compassion for asylum seekers (Surawski, Pedersen, \& Briskman, 2008), many Australians have highly negative or prejudiced attitudes towards them (Markus, 2015). This is despite the fact that their arrival by boat does not violate any international or national law. Indeed, Markus (2015) found that many respondents of a community poll (approximately one-third) believed asylum-seeker boats should be turned back without asylum claims being assessed. We do not go into great detail about Australia's asylum-seeker policies as these can be found elsewhere (e.g., Fleay, 2010); however, suffice to say that they are extremely harsh, designed to both deter and punish asylum seekers who attempt to enter Australia by boat (Penovic, 2016). Furthermore, the fact that Australia's asylum-seeker policy regime (e.g., mandatory detention) is harmful both psychologically and physically to people seeking asylum cannot be disputed (Coffey, Kaplan, Sampson, \& Tucci, 2010; Davidson, Murray, \& Schweitzer, 2008; Steele et al., 2004). In response to various aspects of Australia's asylum-seeker policy, there has been considerable outrage from some quarters, including the Australian Human Rights Commission (2014). Relevantly, psychology's peak body strongly opposes Australia's immigration detention regime (Australian Psychological Society, 2011a, 2011b).

Because very few Australians have contact with asylum seekers, it is likely that much of the information that they receive and espouse comes from commentators and importantly, from politicians via the media (Moloney, 2007). This information is often inaccurate (Suhnan, Pedersen, \& Hartley, 2012) and leads to what some researchers label 'false beliefs' - the acceptance of incorrect information as being true. This is the focus of the present study: the examination of why some people accept false beliefs about asylum seekers as being true and others do not. 


\section{False Beliefs About Asylum Seekers}

There is much false information that exists in the public and political domain about people seeking asylum in Australia. For example, Markus (2015) asked an open-ended question over a number of years regarding the reasons participants in his polls believed asylum seekers would make the journey to Australia by boat. The most common response (involving approximately one half of participants) was to have 'a better life' (p. 45), as opposed to fleeing persecution. This is in fact not the case; over the last decade, most asylum seekers to Australia who arrived by boat have been found to be refugees. There are a number of other false beliefs; for example, 'many asylum seekers come to Australia compared to other Western countries'. This is incorrect; compared to other OECD countries, Australia receives comparatively small numbers of asylum seekers, with the vast majority of the world's refugees residing in developing countries (United Nations Higher Commissioner for Refugees, 2013). Another common false belief is that asylum seekers who arrive by boat are 'illegal'. However, as a signatory to the United Nations Refugee Convention (the Refugee Convention) the 'right to seek asylum' regardless of one's mode of arrival is present in both Australia's domestic law and in international law. Finally, there is a common assumption that 'asylum seekers are safe when they arrive in Indonesia or Malaysia, so travelling to Australia is unnecessary', which in reality is false (Croston \& Pedersen, 2013). Unlike Australia, these countries are not signatories to the Refugee Convention and as such do not have the legal or administrative framework to provide for the protection of refugees. Thus, asylum seekers are considered as 'undocumented immigrants'; they have no access to basic human rights such as work rights, education, or healthcare, and are constantly vulnerable to being arrested and indefinitely detained by authorities (Mathew \& Harley, 2014). Such false beliefs continue to be a common fixture in the discourse surrounding asylum seekers (McKay, Thomas, \& Kneebone, 2012; Sulaiman-Hill, Thompson, Afsar, \& Hodliffe, 2011). It is beyond the scope of this article to outline all false beliefs about asylum seekers to Australia. However, there are a number of other resources that interested readers can access; for example, Andrew and Renata Kaldor Centre for International Refugee Law (n.d.), Asylum Seeker Resource Centre (n.d.), and Buckmaster and Guppy (2014).

In a recent study, the vast majority of participants reported a lack of accurate knowledge about asylum seekers and asylum-seeker issues; interestingly, the knowledge that participants did have corresponded with media reporting on the issue (McKay et al., 2012). This brings us to our next point - the role of the media in the reporting of false beliefs. Several studies have found that the politicians' rhetoric reported in the media relates to the espousing of false beliefs. For example, Pedersen, Watt, and Hansen (2006) found that participants who were more prejudiced against asylum seekers espoused more false beliefs; furthermore, those beliefs were linked to political rhetoric (e.g., asylum seekers are queue jumpers, illegals, and not 'genuine' refugees). There has been limited work conducted on espousing false beliefs, socio-demographic variables, and political orientation. However, in one Australian study, it was found that lower levels of education, right-wing political position, and increased age correlated with false beliefs (Pedersen, Attwell, \& Heveli, 2005). Right-wing orientation was the strongest variable - the only one, in fact, to remain significant in a second regression model. False beliefs were also positively correlated with Australian identity. In a recent study, Anderson (2016) — among other things — found that being male correlated with both implicit and explicit prejudice towards asylum seekers.

\section{Confidence in Espousing False Beliefs}

To date, no research exists linking the acceptance of false beliefs with confidence in such beliefs in the first place. Previous research finds that confidence about one's memory does not reliably predict accuracy (e.g., Brewer \& Weber, 2008; Busey, Tunnicliff, Loftus, \& Loftus, 2000). In another study, Lawson and Strange (2015) investigated memory distortions in the media and found that the lower the accuracy, the higher the level of confidence.

No research exists as to the relationship between false beliefs about asylum seekers and confidence although it is safe to say, based on the above, that the relationship is not a clear one. Specifically, the confidence that individuals have about their beliefs says nothing about the accuracy of those beliefs.

\section{Prejudice}

The Australian public holds diverse views towards asylum seekers, with some people vehemently supporting asylum-seeker rights, other people vehemently opposing asylum-seeker rights, and many people in the middle. However, prejudice levels, or negativity towards asylum seekers, are relatively high compared with other marginalised groups like Indigenous Australians (Pedersen, Clarke, Dudgeon, \& Griffiths, 2005).

The acceptance of false beliefs has been linked with higher levels of prejudice towards asylum seekers in a number of studies (e.g., Suhnan et al., 2012). Most regression studies examining prejudice and false beliefs have been conducted with prejudice as the dependent variable; however, it is worth noting that the relationship between prejudice and false beliefs is likely to be bidirectional. Prejudiced people are more likely to accept false negative information as being true, and being given false negative information can make people prejudiced. One study that examined false beliefs as a dependent variable was Pedersen, Attwell et al. (2005), as discussed previously.

It has been previously argued (e.g., Potter, 1996) that it is unhelpful to make distinctions between statements that are 'true' and statements that are 'false', even though there 
are some statements that are patently untrue; for example, 'There are a lot of asylum seekers coming to Australia compared with other Western countries'. There are some statements, however, that require a more nuanced understanding of refugee movements and issues that can appear as though they are open to interpretation, such as 'Asylum seekers are queue jumpers'. While such statements require deeper understanding and discussion to decipher their inaccuracy, there is uncomplicated agreement that such statements can be objectively falsified (see Parliament of Australia, 2015).

\section{Third-Person Effect}

Given the small number of asylum seekers who arrive in Australia by boat compared to the Australian population, it is reasonable to assume that most people in the community do not have any contact with asylum seekers (Moloney, 2007). Therefore, where does information that community members hold about asylum seekers originate? We argue that it is likely that such information comes from the media and, in particular, from politicians (Every \& Augoustinos, 2008). Yet, not everybody accepts the information that is given to them. So, is there a media-related, social-psychological process occurring that might influence people to either accept or reject false information?

One variable that might affect how much inaccurate information about asylum seekers is accepted as true is the 'third-person effect' or 'third-person hypothesis', as coined by its founder Davison (1983). As he defined it, in its broadest formulation, this hypothesis predicts that people will tend to overestimate the influence that mass communications have on attitudes and behavior of others' (p. 3). A more recent definition, which we rely on, defines the third-person effect thus: '.. a tendency for people to believe that the media have a greater effect on the beliefs, attitudes and behaviour of other people than on themselves' (Duck \& Mullin, 1995, pp. 77-78).

As occurs with many concepts, it is clear that context is important with regard to the third-person effect. It is more likely to occur when the topic is important to people and when they perceive the message as being negatively biased (Perloff, 1993). It has been found to be stronger when using college samples, possibly because college students think that they are more intelligent than the average population (Paul, Salwen, \& Dupagne, 2000). It has been found to be stronger when the targets are perceived as vulnerable (Sun, Pan, \& Shen, 2008). These authors also found that the effect was strongest with undesirable and/or ambiguous influences (coined 'the negative-influence corollary' by Gunther and Storey, 2003, p. 200). The impact of context on the third-person effect has also been addressed by other authors. For example, Duck and Mullin (1995) found that the effect is not universal; it depends on media context (negative, positive, public service campaigns). They found the effect was stronger in a negative context, although there was a significant effect for the other two contexts.

\section{Overview}

There are a number of studies examining factors underlying prejudice towards asylum seekers. Past research finds that a significant correlate of higher levels of prejudice is the acceptance of false beliefs as being true. There is a dearth of studies, however, examining what predicts false beliefs; this is the focus of the present study.

We previously outlined research indicating that many Australians do not have contact with asylum seekers and are therefore likely to rely on the media for information. We also outlined research indicating that message desirability is a moderator of the third-person effect; specifically, the third-person effect is more likely to occur if the message is perceived as undesirable or negative. Given that false beliefs about asylum seekers are generally negative in nature and asylum seekers are seen as undesirable, it may well be that people who have a tendency to overestimate the impact of mass communications on others might also be more likely to espouse false beliefs. This line of research is potentially important, given that research finds that people are influenced by what others are thinking and this can affect intergroup relations (Putra, 2014).

In short, our study adds to the present literature on the prediction of false beliefs by investigating a number of variables that have not been linked with this before. In particular, we investigated the relationship between false beliefs and confidence in such false beliefs. We also investigated the relationship between false beliefs and the third-person effect (media). This latter research question makes a unique contribution to the thirdperson effect literature by including the third-person effect (politicians).

Specifically, we first examined the third-person effect that involves the disparity between media messages on oneself versus others (Liu \& Lo, 2014). Based on previous research (e.g., Duck \& Mullin, 1995; Perloff, 1993), we hypothesised that participants would be more likely to report that other people would be more influenced by (a) politicians and (b) media reporting than themselves. Previous research has not examined the third-person effect with regard to asylum-seeker issues, and there is no research looking at the third-person effect with regard to politicians' rhetoric. Second, we investigated the correlations between false beliefs and a number of other independent variables that might relate to such beliefs. Specifically, we examined whether the acceptance of false beliefs as being true related to (a) confidence in holding false beliefs, (b) prejudice towards asylum seekers, (c) the third-person effect, both media and politician related, and (d) sociodemographic and political orientation variables. Finally, we investigated by way of regression the predictive power of the social psychological variables outlined above that 
were correlated with false beliefs while controlling for prejudice and socio-demographics and political orientation (previously found relationships).

Our rationale for choosing the variables that we did was that there are two disparate bodies of literature that may potentially relate to the acceptance of false information as being true (confidence and the third-person effect). We were interested in whether either, or both, bodies of research were relevant to false beliefs. In essence, we used a combination of two perspectives to provide more insight into the topic. ${ }^{1}$

\section{Method}

\section{Participants}

A total of 164 Australian participants were recruited via Qualtrics, an online community survey pool. Participants were aged between 20 and 83 years with a median age of 56; this is older than the median age of the Australian population which is 37 (Australian Bureau of Statistics [ABS], 2014). Approximately half the participants (51\%) were female, which is in line with ABS (2014) statistics. Onequarter of the participants $(25 \%)$ had left political leanings compared with just over one-quarter $(29 \%)$ who had right political leanings (a full description of political leanings is further described later in this article). Almost half of the participants $(46 \%)$ reported that they had neither left or right leanings. There was a wide spread of participant education, with approximately one-quarter (26\%) completing secondary school only and almost a quarter $(23 \%)$ had, or were in the process of completing, a bachelor degree. The rest did not complete secondary school, completed or were in the process of completing vocational training or undergraduate diploma, or they had a higher degree. Thus, $63 \%$ of our participants had part or completed post-school qualifications. This figure is similar to the general population; the ABS (2016) found that $59 \%$ of Australians had a post-school qualification.

Most participants were Caucasian/European (83\%) with the rest being Aboriginal and/or Torres Strait Islander, Asian, Indian, Middle Eastern, or 'other'. Almost half of the sample ( $48 \%$ ) was Christian, followed by those who had no religion (37\%). The remainder were Buddhist, Hindu, Jewish, Muslim, or 'other'. The participants came from all states in Australia. Most came from Queensland (33\%), Victoria (24\%), and New South Wales (22\%). The remainder came from the Australian Capital Territory, South Australia, the Northern Territory, Western Australia, and Tasmania.

\section{Measures}

Demographics. Participants were asked a series of questions relating to their demographics. Participants stated their age in years, their gender $(1=$ female, $2=$ male $)$, their ethnic background $(1=$ Aboriginal/Torres Strait Islander, $2=$ African, $3=$ Asian, $4=$ Caucasian/European, $5=$ Indian, $6=$ Middle Eastern, 7 = Pacific Islanders, or
Other $)$, their religion $(1=$ Buddhist, $2=$ Christian, $3=$ Hindu, 4 = Jewish, 5 = Muslim, $6=$ no religion, or Other), education level $(1=$ Did not complete secondary school through to $6=$ Higher degree) and their political preference $(1=$ strongly left, through to $5=$ strongly right, or $6=$ don't care). Specifically, they were asked: 'How would you describe your political preferences on most issues? Please tick one box that comes closest to your view. "Right or right-wing" views mean a conservative political viewpoint; and "Left or left-wing" means the opposite.' They also reported which state they lived in.

We then explained what an asylum seeker was for the purposes of our study: 'An asylum seeker is someone who is seeking international protection but whose claim for refugee status has not yet been determined. There are also asylum seekers who arrive by plane but we are only looking at those who try to arrive by boat in this study.'

Third-person questions. Two questions based on Liu and Lo (2014) were asked with regard to the influence of the news and politicians respectively (making a total of four questions). The first was 'To what degree does news coverage inform your views on asylum seekers?' The second was 'To what degree does news coverage inform the views of other Australians on asylum seekers?' The third was 'To what degree does what you hear from politicians inform your views on asylum seekers?' The fourth was 'To what degree does what you hear from politicians inform the views of other Australians on asylum seekers?' Participants answered on a 7-point Likert scale, with 1 being not at all and 7 being very much. To create the third-person variables, we subtracted 'the effect of self from' the effect of others' as per Liu and Lo (2014) and Robinson and Umphrey (2006). Thus, the analysis involved an analysis of two scores: third-person effect news and third-person effect politicians.

False beliefs. Ten questions based on Croston and Pedersen (2012) were then asked of participants; for example, 'Asylum seekers are safe when they arrive in Indonesia or Malaysia so travelling to Australia is unnecessary.' Participants answered on a 7-point Likert scale with 1 being strongly disagree and 7 being strongly agree. Three items were reversed so that high scores equalled high belief in false beliefs. Croston and Pedersen found that reliability for the scale was satisfactory $(\alpha=0.88)$.

Confidence in false beliefs. After the false belief questions, participants were asked how confident they were about the answers they just gave. There was one question: 'How confident of your answers to the above 10 questions are you?' Participants answered on a 7-point Likert scale, with 1 being not at all confident and 7 being very confident.

Prejudice. This six-item, semantic-differential scale, adapted from Wright, Aron, McLaughlin-Volpe, and Ropp (1997), was used to measure prejudice towards asylum seekers. Participants indicated on a Likert scale ranging from 0 to 10 how they felt about asylum seekers with six paired adjectives; for example, 'negative-positive', with 
higher scores indicating higher prejudice. Previous research finds this prejudice scale reliable; for example, Turoy-Smith, Kane, and Pedersen (2013), with $\alpha=.93$ with respect to refugees in Australia.

First, we did a pilot study to test the questionnaire using a convenience sample. The total sample involved 69 participants; minor changes were made to the questionnaire after such piloting to make the questions more understandable to the general public.

For the study proper, participants were drawn from around Australia during June 2015 through Qualtrics, an online community survey service. Participants were sent an email regarding the topic of the study and could either complete the questionnaire or not. All participants were given the same questionnaire with the measures in this order: socio-demographics, third-person questions, the false belief scale, and confidence in false beliefs and prejudice. The survey took approximately 15 minutes to complete.

\section{Results \\ Descriptive Variables}

One item in the false belief scale (i.e., Giving Temporary Protection Visas will not stop the boats) lowered reliability and was therefore removed, leaving a total of nine items. However, no other item needed to be removed from any of the scales. As set out in Table 1, we found that reliability was satisfactory for all three scales (between $\alpha=$ .71 and $\alpha=.95$ ). With respect to our dependent variable, we note that many participants held some false beliefs about asylum seekers, with the mean being 4.61; indeed, most scored above the midpoint. While a minority of participants $(25 \%)$ scored below the midpoint, $7.3 \%$ scored on the midpoint and the remaining two-thirds (67.7\%) scored above the midpoint. Interestingly, participants were relatively confident about their answers regarding false beliefs, with most participants scoring high on this variable. The participants scored above the midpoint on the prejudice scale, and there was a greater discrepancy between extreme scores with the third-person effect (politician) compared with the third-person effect (media).

\section{Aim 1: The Third-Person Effect}

We hypothesised that participants would be more likely to report that other people would be more influenced by (a) politicians and (b) media reporting than themselves. First, we investigated whether participants would be more likely to report that other people would be more likely to be influenced by news media reporting than themselves. Results indicated no significant third-person effect, $t(163)=$ $1.8, p=.074$. Second, we investigated whether participants would be more likely to report that other people would be more likely to be influenced by politicians' rhetoric than themselves. Results indicated a significant third-person effect, $t(163)=4.0, p<.001)$. This effect can be described as small at $r=.10$ (see Cohen, 1988). In other words, partic- ipants were significantly more likely to report that other people would be influenced by politicians than themselves.

\section{Aim 2: Correlations Between Variables}

First, we look at the correlation matrix. As can be seen in Table 2, there was a large relationship between false beliefs and prejudice towards asylum seekers. There was a moderate relationship between false beliefs and confidence in holding such false beliefs and right-wing political views. There was a small but significant negative correlation with regard to the third-person effect (politicians) as well as all socio-demographics. That is, people who scored high on false beliefs were less likely to believe that politicians had a bigger effect on other people compared with people who scored low on false beliefs. They were also more likely to be older males with lower levels of education.

\section{Aim 3: Prediction of False Beliefs}

We then investigated by way of multiple regression the predictive power of the social-psychological variables outlined above while controlling for socio-demographics, political orientation, and prejudice. We controlled for prejudice because of the well-established relationship between prejudice and false beliefs, and controlled for sociodemographics and political orientation because this relationship has been investigated before (Pedersen et al., 2004), and it is sometimes useful to compare similar studies. The new social-psychological variables were of more interest to us than previously found relationships.

In first regression model, prejudice and the sociodemographic variables accounted for a significant $39.7 \%$ of variance; however, only prejudice and political orientation were significant when all variables were included $\left(R^{2}\right.$ change $=.397$; see Table 3$)$. This indicated that people who scored high on false beliefs also scored high on prejudice and were more likely to support right-wing politics. When all the social-psychological variables were added in the second regression model, the amount of variance accounted for significantly increased by $4.3 \%$, indicating that people who scored high on false beliefs were again more likely to score high on prejudice and be right wing politically $\left(R^{2}\right.$ change $\left.=.439\right)$. They were also more likely be confident in their answers to the false beliefs and were more likely to be believe that others were more susceptible to being influenced by politicians than themselves (the third-person effect). Overall, the final model accounted for a significant $43.9 \%$ of variance, which according to Cohen (1988) can be considered a large effect size.

\section{Discussion}

In the present study, we were interested in what would predict false beliefs about asylum seekers in Australia using two different theoretical concepts: confidence in one's opinion and the third-person effect. We found modest support for the third-person effect (politicians) and 
Table 1

Descriptive Statistics for Dependent and Predictor Variables

\begin{tabular}{llccc}
\hline & $M(S D)$ & Range & Reliability & Number of items \\
\hline False beliefs & $4.61(1.20)$ & $1.22-6.89$ & $\alpha=.85$ & 9 \\
Confidence in false beliefs & $5.65(1.24)$ & $2-7$ & - & 1 \\
Prejudice & $6.32(2.34)$ & $1.17-11$ & $\alpha=.95$ & 6 \\
Third-person effect media & $0.159(1.13)$ & $-.3 .00-4.00$ & - & 2 \\
Third-person effect politicians & $0.329(1.16)$ & $-3.00-5.00$ & - & 2 \\
\hline
\end{tabular}

Table 2

Correlation Matrix

\begin{tabular}{|c|c|c|c|c|c|c|c|c|c|}
\hline & 1 & 2 & 3 & 4 & 5 & 6 & 7 & 8 & 9 \\
\hline 1. False beliefs & 1 & $\begin{array}{l}.319^{* *} \\
{[.171} \\
.459]\end{array}$ & $\begin{array}{l}.529^{* *} \\
{[.366} \\
.685]\end{array}$ & $\begin{array}{r}-.063 \\
{[-.221} \\
.093]\end{array}$ & $\begin{array}{l}-.181^{*} \\
{[-.345} \\
-.029]\end{array}$ & $\begin{array}{l}.453^{* *} \\
{[.325} \\
.571]\end{array}$ & $\begin{array}{c}-.161^{*} \\
{[-.307} \\
.004]\end{array}$ & $\begin{array}{l}.187^{*} \\
{[.028} \\
.347]\end{array}$ & $\begin{array}{l}-.188^{*} \\
{[-.331} \\
-.034]\end{array}$ \\
\hline $\begin{array}{l}\text { 2. Confidence in false } \\
\text { beliefs }\end{array}$ & & 1 & $\begin{array}{l}.311 * * \\
{[.171} \\
.456]\end{array}$ & $\begin{array}{r}-.047 \\
{[-.195} \\
.091]\end{array}$ & $\begin{array}{r}.015 \\
{[-.130} \\
.157]\end{array}$ & $\begin{array}{l}.143 \\
{[.020} \\
.269]\end{array}$ & $\begin{array}{r}.014 \\
{[-.136} \\
.153]\end{array}$ & $\begin{array}{l}.210^{* *} \\
{[.067, .347]}\end{array}$ & $\begin{array}{r}-.125 \\
{[-.277} \\
.030]\end{array}$ \\
\hline 3. Prejudice & & & 1 & $\begin{array}{r}-.027 \\
{[-.168} \\
.126]\end{array}$ & $\begin{array}{r}-.043 \\
{[-.194} \\
.120]\end{array}$ & $\begin{array}{l}.255^{*} \\
{[.107} \\
.396]\end{array}$ & $\begin{array}{l}-.173^{*} \\
{[-.317,-.032]}\end{array}$ & $\begin{array}{l}.195^{*} \\
{[.045} \\
.336]\end{array}$ & $\begin{array}{r}-.086 \\
{[-.248} \\
.064]\end{array}$ \\
\hline $\begin{array}{l}\text { 4. Third-person effect } \\
\text { news } \\
\text { 5. Third-person effect } \\
\text { politicians }\end{array}$ & & & & 1 & $\begin{array}{c}.280^{* *} \\
-.002, .548] \\
1\end{array}$ & $\begin{array}{l}-.013 \\
{[-.170, .188]} \\
\quad .038 \\
{[-.247, .147]}\end{array}$ & $\begin{array}{l}-.011 \\
{[-.171, .146]} \\
\quad .148 \\
\quad .026, .278]\end{array}$ & $\begin{array}{l}-.059 \\
{[-.206, .096]} \\
-.058 \\
{[-.206, .078]}\end{array}$ & $\begin{array}{l}-.056 \\
{[-.210, .091]} \\
-.062 \\
{[-.204, .102]}\end{array}$ \\
\hline 6. Political position & & & & & & 1 & $\begin{array}{r}-.098 \\
{[-.252} \\
.068]\end{array}$ & $\begin{array}{l}.166^{*} \\
{[.019} \\
.297]\end{array}$ & $\begin{array}{l}-.219^{* *} \\
{[-.354,-.068]}\end{array}$ \\
\hline 7. Education & & & & & & & 1 & $\begin{array}{l}-.168^{*} \\
{[-.302,-.022]}\end{array}$ & $\begin{array}{l}-.023 \\
{[-.177, .136]}\end{array}$ \\
\hline 8. Age & & & & & & & & 1 & $\begin{array}{l}-.268^{* *} \\
{[-.400,-.110]}\end{array}$ \\
\hline 9. Gender & & & & & & & & & 1 \\
\hline
\end{tabular}

Note: Confidence intervals and standard errors based on 1,000 bootstrap samples. Most relevant significant relationships are shown in bold type for ease of reference.

confidence in the multiple regression analysis. We will discuss these findings in full below, together with the practical implications and conclusions of our study. But first, it is worth noting that the acceptance of false information about asylum seekers was quite prevalent in this community sample, with most participants (approximately two-thirds) scoring above the midpoint of the scale. Thus, our view of the importance of investigating false beliefs is iterated.

\section{The Third-Person Effect}

The second analysis we conducted involved the thirdperson effect; our prediction that participants would be more likely to report that other people would be more influenced by (a) politicians and (b) media reporting than themselves was only partially supported. There was a significant (but small) effect with respect to the questions relating to politicians but no significant effect with respect to the media generally. This lack of effect might be due to the fact that - depending on the media outlet one is predominately engaging with - not all media is negative about asylum seekers (see Cooper, Olejniczak, Lenette, \& Smedley, 2016; Gordon, 2015; Mitchell, 2015).
Future research might seek to separate out the media outlet to see whether this has an impact on the third-person effect. Also, some research finds (in particular, Paul et al., 2000) that the third-person effect is weaker in community samples compared with student samples, and ours was a community sample. The fact that there was no effect for third-person effect (news) and only a small effect for thirdperson effect (politicians) could be considered surprising given the topic matter. Duck and Mullin's (1995) study found that the third-person effect was more pronounced when participants considered the impact of negative content such as racism because of self-serving motivations. Yet, it is very likely that our more negative participants would not see their attitudes as racist; most people do not (see Dunn, Forrest, Burnley, \& McDonald, 2004).

The fact that the politician third-person effect was significant and the media third-person effect was not can only be speculated on. However, it may relate to some recent findings in the United States that news sources were trusted more than other sources even though negativity about news sources was at an all-time high (Pew Research Center, 2011). So, it may be that a similar situation occurs in Australia, where politicians are trusted less than the news generally. Indeed, recent research indicates 


\begin{tabular}{|c|c|c|c|c|c|}
\hline Variables entered & & $\mathrm{b}$ & SE b & Beta & $p$ \\
\hline \multicolumn{6}{|l|}{ First model } \\
\hline & (Constant) & $\begin{array}{l}2.338 \\
{[1.185,3.436]}\end{array}$ & .574 & & $p=.001$ \\
\hline & Age & $\begin{array}{c}.002 \\
{[-.009, .013]}\end{array}$ & .006 & .021 & $p=.753$ \\
\hline & Sex & $\begin{array}{l}-.185 \\
{[-.489, .141]}\end{array}$ & .158 & -.077 & $p=.264$ \\
\hline & Political preference & $\begin{array}{l}.401 \\
{[.188, .583]}\end{array}$ & .101 & .319 & $p=.002$ \\
\hline & Education & $\begin{array}{l}-.042 \\
{[-.143, .058]}\end{array}$ & .052 & -.054 & $p=.431$ \\
\hline & Prejudice & $\begin{array}{l}.219 \\
{[.135, .308]}\end{array}$ & .044 & .427 & $p=.001$ \\
\hline \multirow[t]{9}{*}{ Second model } & (Constant) & $\begin{array}{l}1.907 \\
{[.706,3.128]}\end{array}$ & .645 & & $p=.005$ \\
\hline & Age & $\begin{array}{c}-.001 \\
{[-.012, .010]}\end{array}$ & .006 & -.010 & $p=.872$ \\
\hline & Sex & $\begin{array}{l}-.198 \\
{[-.419, .110]}\end{array}$ & .158 & -.083 & $p=.223$ \\
\hline & Political preference & $\begin{array}{l}.387 \\
{[.193, .567]}\end{array}$ & .097 & .307 & $p=.002$ \\
\hline & Education & $\begin{array}{l}-.037 \\
{[-.136, .062]}\end{array}$ & .052 & -.048 & $p=.479$ \\
\hline & Prejudice & $\begin{array}{c}.197 \\
{[.111, .290]}\end{array}$ & .045 & .383 & $p=.001$ \\
\hline & Third-person effect: Politics & $\begin{array}{l}-.170 \\
{[-.348,-.039]}\end{array}$ & .081 & -.150 & $p=.032$ \\
\hline & Third-person Effect News & $\begin{array}{l}-.014 \\
{[-.135, .122]}\end{array}$ & .068 & -.013 & $p=.828$ \\
\hline & Confidence in myths & $\begin{array}{c}.145 \\
{[-.013, .271]} \\
\end{array}$ & .065 & .150 & $p=.034$ \\
\hline
\end{tabular}

Note: Confidence intervals reported in parentheses. Confidence intervals and standard errors based on 1,000 bootstrap samples.

$R^{2}=.397$ after the first model; $R^{2}=.439$ after the second model. Significant relationships are shown in bold type for ease of reference.

that a very small minority of Australians - 5\% - trust the government (Evans, Stoker, \& Halupka, 2016). Future research is needed to explore this possible explanation further.

\section{Relationship Between False Beliefs and the Independent Variables}

Our next analysis investigated the correlations between false beliefs and a number of other variables relating to such beliefs (confidence in false beliefs; prejudice; the third-person effect, both media and politician; sociodemographic variables; and political orientation).

With regard to the socio-demographics and political orientation, we found that participants who scored high on false beliefs tended to be older with low levels of education, and who leaned towards the political right (in line with Pedersen, Attwell et al., 2005). They also tended to be males, in line with Anderson (2016). Thus, there were similarities in the relationship between false beliefs and socio-demographic variables with previous work.

False beliefs were also correlated with confidence in false beliefs, prejudice, and the third-person effect (politicians). These three variables were also significant in the regression, which we will now turn to.
Prejudice significantly predicted the acceptance of false information as being true. This is not surprising given the amount of research finding such a link (e.g., Suhnan et al., 2012). As noted previously, this is likely to be a bidirectional relationship; future research should thus attempt to disentangle the direction of these variables.

Confidence in false beliefs significantly predicted the acceptance of those false beliefs as being true. Interestingly, participants were generally quite confident about their answers regarding the false belief scale, with most participants scoring above the midpoint. Our study supports other research that finds that confidence does not mean increased accuracy (Brewer \& Weber, 2008). However, the present research takes these findings further in the context of asylum seekers, finding that the more confident people feel about their false beliefs, the more life is given to them - they are more likely to espouse them. Our results support the findings of Lawson and Strange (2015), who investigated memory distortions in the media. Like us, they found that the lower the memory accuracy, the higher the level of participants' confidence levels. In other words, participants who were more confident were less accurate.

Third-person effect (politicians) also significantly predicted false beliefs. Contrary to expectation, the more 
people espoused false beliefs, the less they reported being affected by the third-person effect. So, they did not believe that politicians had more of an effect on others compared to themselves. A different way of reading the same results is that the less people espoused false beliefs, the more they believed that others would be more likely to be influenced by politicians. So, they might perceive that the less accurate participants would see the political rhetoric about asylum seekers as 'the truth' and are fine with accepting that politicians 'inform their views on asylum seekers' as the questionnaire item states.

At the same time, it might be that the more knowledgeable participants are getting their information from more legitimate sources. For example, participants who scored relatively low on false beliefs could read well-publicised books such as Dark Victory (Marr \& Wilkinson, 2003) or Human Rights Overboard (Briskman, Latham, \& Goddard, 2008). They could also be reading myth-busting sites (e.g., Asylum Seeker Resource Centre, n.d.) or any number of journal articles. Thus, they may be more likely to think that they are not affected by politicians' rhetoric while others are indeed affected. Again, further research is necessary to address this hypothesis directly.

\section{Practical Implications}

From a theoretical viewpoint, our research indicates that two disparate bodies of research (confidence in one's opinions and the third-person effect) are both relevant to the acceptance of false beliefs being true. However, there are also practical implications arising from our article. The first is the degree of false beliefs espoused by many participants and the fact that they are reinforced by the media and politicians (see Every \& Augoustinos, 2008). In one study, it was found that if you consistently hear something, false or otherwise, you are much more likely to remember it (Skurnik, Yoon, Park, \& Schwarz, 2005). In the Skurnik et al. (2005) study, participants were told that information was false. In the short term, they remembered this correctly. But over time, participants - in particular, the older ones - remembered the information incorrectly; that is, they remembered the false information. With most of our participants, it is not likely that they were told that the information that they held was false by politicians or the media; or if they were told, they may not accept it. As found by Croston and Pedersen (2013), participants who initially disagreed with an article correcting false beliefs recalled less accurate information. This is in line with what is known as 'confirmation bias', which is the well-established tendency to interpret information in line with one's own previous views (Nickerson, 1998). The role of memory distortion is well documented (see Bigler \& Liben, 1993; Frawley, 2008). As Schacter (2012) puts it, memories are critical to engage with our world, but they are also prone to distortion. Thus, he argues, our memories are both adaptive yet have considerable pitfalls. In another study, it was found that when children were repeatedly given in- formation about an event that did not occur, they were more likely to report this event as being true at a later date compared with children who were given less information (Otgaar, Smeets, \& Peters, 2012). Many of the false beliefs about asylum seekers are in fact repeatedly given by Australian politicians through the media (e.g., 'genuineness' of asylum seekers' claims).

The second issue is the finding that right-wing political orientation significantly predicted false beliefs; this has ramifications for people who design and implement interventions to address prejudice. It is difficult to run campaigns in this field without mentioning politicians and political policy, given the relationship between politicians' rhetoric and the acceptance of false information as being true (Pedersen et al., 2006). We would suggest that antiprejudice strategists think carefully about how this should be done; the very people that they might be trying to influence might be so offended that they stop listening. We are not suggesting that the subject be avoided; we are simply suggesting that a nuanced approach should be used in discussing the topic.

The third issue is the confidence that people have in false beliefs. People who are more likely to espouse false beliefs have more confidence in them. This, coupled with the preceding findings, means that - again — those working to address negativity towards asylum seekers need to tread gently when dealing with these false beliefs. The fact that many community members are likely to have confidence in their beliefs means that it will take sensitive work to have them consider beliefs based on evidence that participants are likely not to have considered. Simply saying to people that they are wrong or that they hold incorrect information is unlikely to sway their opinion. We propose that a more effective way is to discuss these issues calmly, using a number of sources; furthermore, it may be that they need to go away and check these sources themselves. If giving an antiprejudice workshop, it would also be better to have a number of speakers giving information. Indeed, there are a number of organisations that conduct interventions aimed at increasing positivity and decreasing false beliefs, and they often use multiple speakers with a pro-asylum seeker focus. For example, both of the authors in the present study were involved in a communityeducation program that included a breakfast-information session with a number of speakers: an asylum seeker, a human rights lawyer, and a social psychologist. Imparting factual information was an important part of this event, and it was delivered from a number of sources.

However, it is worth noting that disputing false beliefs is only part of the picture (albeit an important one) when engaging in an antiprejudice strategy. There are other important factors that need to be taken into account (see Pedersen \& Hartley, 2015, for an overview of these). In particular, we note that what we see as 'rational communication' is unlikely to be enough to sway both politicians and the general public. One only has to look at the U.S. politics to see the comment by Kellyanne Conway 
(President Trump's aide) that the media distorts reality and that there were 'alternative facts' (see Wood, 2017). It has been further argued that there is political mileage to be had from scapegoating asylum seekers (Marr \& Wilkinson, 2003); thus, anti-asylum seeker rhetoric can be seen to be functional. We do not argue that facts alone will change policy. Instead, facts are part of the picture but a very necessary one. As has been shown in recent years, politicians do not always 'toe the party line' and this has led to policy change. This issue aside, the more confident people are regarding their views, the more skill is needed to counter them, and this needs to be taken into account.

The final issue we would like to discuss is the thirdperson effect findings. Participants who accepted false information as being true were less likely to believe that politicians have more of an effect on other people's views compared to their own views. This might be due to the high false-belief participants seeing the political rhetoric about asylum seekers as 'the truth', thus diminishing the third-person effect with an expectation that most rightthinking individuals will accept it. Alternatively, it might be that the finding is led by low false-belief participants who were less likely to accept the false beliefs. Only future research can untangle this question. Regardless of the direction of the relationship, we suggest that in an antiprejudice intervention, a full, frank and diplomatic discussion about the role of political rhetoric needs to be held.

\section{Strengths, Limitations, and Future Research}

There were a number of limitations relating to the present study. The first is that although we had hoped for a representative sample, our participants were generally older Australians with an average age of 54. Given that the present study found that increased age related to false beliefs, it might be that a younger sample might react differently to the questions asked. Also, the third-person effect questions were quite general, so it would be interesting to break them up into different types of media and political party. It would be interesting to follow this up: Does political rhetoric seem desirable or positive by some participants and, if so, does this relate to the third-person effect?

However, there were also strengths to our research. Although our sample was older than the general population, it was generally a good representation of the Australian population with respect to gender and education (ABS, 2014,2016 ). It was also the only research apart from Pedersen, Attwell et al. (2005) to investigate false beliefs as a dependent variable; unfortunately, we found that 10 years after this study, a great deal of false information still exists. It is also the first study to look at the relationship between false beliefs, confidence in such myths, and prejudice. Furthermore, no research has examined the third-person effect with regard to asylum-seeker is- sues or the third-person effect with regard to politicians' rhetoric.

\section{Conclusion}

The prevalence of false beliefs in the community is a problem for the smooth functioning of Australian society as it leads to disquiet and resentment that then affects asylumseeker and refugee communities. This resentment against asylum seekers, based on inaccurate information, is unnecessary although functional in some respects (we deal with this later in this article). We have also shown in our article that people who espouse false beliefs are more confident in their views; this has implications for antiprejudice strategists trying to reduce such false beliefs. With regard to the third-person findings, we add to previous research that finds that such beliefs must be viewed within the context in which they arise. More research is necessary on this point.

It is also worth noting that although there is some positive asylum-seeker media, a great deal is negative (see, e.g., Moloney, 2007, with respect to politically satirical cartoons). The two major political parties prioritise policies aimed at deterring asylum seekers from getting on boats and emphasise the role of people smugglers in this process; in so doing, the humanity of asylum seekers is diminished. This results in most politicians' rhetoric influencing many Australians to feel threatened by asylum seekers (Suhnan et al., 2012). However, this does not mean that antiprejudice strategists and advocates should give up. We need to change the system from the bottom up and that is where the use of valid research is important - so we know how to do it. For example, in a recent Australian study, Anderson, Stuart, and Rossen (2015) found that macro justice principles (i.e., principles involving equal resource distribution) predicted positivity towards asylum seekers. We need to work with researchers, advocates and organisations to make societal change. As found in 2005 when a number of Australian Liberal Party MPs (known as the 'Rebels') spoke out against their leader (John Howard) about the deleterious conditions of mandatory detention after consistent lobbying by constituents, the giving of information to politicians can influence policy. However, it needs to be done in a way where they will actually listen. This is where research can be influential. In short, doing nothing is simply not an option, and we hope that our research can help - even if in a very small way - to achieve this.

\section{Acknowledgments}

We thank Emma Dugandzic, Kiri-Lee George, Samantha Hurley, Jacob Lawrence, Jacob Mattioli, Hannah Nyx, Amy Ritchie, and Jessica Giacoman for their work collecting and inputting the data together with insightful comments during the year of their thesis. We note that the data were collected at the School of Psychology and Exercise Science, Murdoch University, Western Australia. 


\section{Endnote}

1 We note that we were also interested in the relationship between exposure of media and false beliefs (we measured newspaper, television, the internet, and radio). However, as there was no effect, we did not include this aspect in the main study but note the results in an effort not to add to the 'file drawer problem'.

\section{References}

Anderson, J.R. (2016). Implicit and explicit attitudes towards asylum seekers in Australia: Demographic and ideological correlates. Australian Psychologist. doi:10.1111/ap.12229

Anderson, J.R., Stuart, A., \& Rossen, I. (2015). Not all negative: Macro justice principles predict positive attitudes towards asylum seekers in Australia. Australian Journal of Psychology, 67, 207-213.

Andrew and Renata Kaldor Centre for International Refugee Law. (n.d.). Debunking myths on refugees and asylum seekers. Retrieved from http://www.kaldorcentre. unsw.edu.au/publication/debunking-myths

Asylum Seeker Resource Centre. (n.d.). Myth busters and fact sheet. Retrieved from http://www.asrc.org.au/ pdf/myths-facts-solutions-info_.pdf

Australian Bureau of Statistics (ABS). (2014). Australian historical populations statistics (Cat. no. 3105.0.65.001). Retrieved from: http://www.abs.gov.au/ AUSSTATS/abs@.nsf/mf/3105.0.65.001

Australian Bureau of Statistics (ABS). (2016). Education and work, Australia, May 2015 (Cat. no. 6227.0). Retrieved from http://www.abs.gov.au/ausstats/abs@.nsf/mf/6227.0

Australian Human Rights Commission, (2014). The forgotten children: National inquiry into children in immigration detention. Retrieved from https://www.humanrights.gov.au/sites/ default/files/document/publication/forgotten_children_ 2014.pdf

Australian Psychological Society. (2011a). Joint Select Committee on Australia's Immigration Detention Network. Melbourne, Australia: Australian Psychological Society.

Australian Psychological Society. (2011b). Psychological wellbeing of refugees and asylum seekers in Australia. Retrieved from https://www.psychology.org.au/Assets/Files/Positionstatement-refugee-2011.pdf

Bigler, R.S., \& Liben, L.S. (1993). A cognitive-developmental approach to racial stereotyping and reconstructive memory in Euro-American children. Child Development, 64, 15071518.

Brewer, N., \& Weber, N. (2008). Eyewitness confidence and latency: Indices of memory processes not just markers of accuracy. Applied Cognitive Psychology, 22, 827-840.

Briskman, L., Latham, S., \& Goddard, (2008). Human rights overboard: Seeking asylum in Australia. Melbourne, Australia: Scribe.

Buckmaster, L. \& Guppy, J. (2014). Australian Government assistance to refugees: Fact v fiction. Background note. Canberra, Australia: Austrlaian Government. Retrieved from
http://www.aph.gov.au/About_Parliament/Parliamentary_ Departments/Parliamentary_Library/pubs/rp/rp1415/ AustGovAssist-refugees

Busey, T., Tunnicliff, J., Loftus, G., \& Loftus, E. (2000). Accounts of the confidence-accuracy relation in recognition memory. Psychonomic Bulletin \& Review, 7, 26-48.

Coffey, G., Kaplan, I., Sampson, R., \& Tucci, M.M. (2010). The meaning and mental health consequences of long-term immigration detention for people seeking asylum. Social Science and Medicine, 70, 2070-2079.

Cohen, J. (1988). Statistical power analysis for the behavioral sciences (2nd ed.). Hillsdale, NJ: Erlbaum.

Cooper, S., Olejniczak, E., Lenette, C., \& Smedley, C. (2016). Media coverage of refugees and asylum seekers in regional Australia: A critical discourse analysis. Media International Australia, 162, 78-89, 1329878X16667832

Croston, J., \& Pedersen, A. (2013). 'Tell me what I want to hear': Motivated recall and attributions in media regarding asylum seekers. Australian Journal of Psychology, 65, 124-133.

Davidson, G.R., Murray, K.E., \& Schweitzer, R. (2008). Review of refugee mental health and wellbeing: Australian perspectives. Australian Psychologist, 43, 160-174.

Davison, W.P. (1983). The third-person effect in communication. Public Opinion Quarterly, 47, 1-15.

Duck, J.M., \& Mullin, B.A. (1995). The perceived impact of the mass media: Reconsidering the third person effect. European Journal of Social Psychology, 25, 77-93.

Dunn, K.M., Forrest, J., Burnley, I., \& McDonald, A. (2004). Constructing racism in Australia. Australian Journal of Social Issues, 39, 409-430.

Evans, M., Stoker, G., \& Halupka, M. (2016, May 3). Now for the big question: who do you trust to run the country? The Conversation. Retrieved from https://theconversation. $\mathrm{com} /$ now-for-the-big-question-who-do-you-trust-to-runthe-country-58723

Every, D. and Augoustinos, M. (2008). Constructions of Australia in pro- and anti-asylum seeker discourse. Nations and Nationalism, 14, 562-580.

Frawley, T.J. (2008). Gender schema and prejudicial recall: How children misremember, fabricate, and distort gendered picture book information. Journal of Research in Childhood Education, 22, 291-303.

Fleay, C. (2010). Australia and human rights: Situating the Howard government. Newcastle upon Tyne, UK: Cambridge Scholars Publishing.

Gordon, M. (2015, September 26). Despair reigns over Manus' forgotten people. Sydney Morning Herald. Retrieved from http://www.smh.com.au/it-pro/despair-reigns-over-manusforgotten-people-20150924-gjtqu5

Gunther, A.C., \& Storey, J.D. (2003). The influence of presumed influence. Journal of Communication, 53, 199-215.

Lawson, V.Z., \& Strange, D. (2015). News as (hazardous) entertainment: Exaggerated reporting leads to more memory distortion for news stories. Psychology of Popular Media Culture, 4, 188-198. 
Liu, X., \& Lo, V.H. (2014). Media exposure, perceived personal impact, and third-person effect. Media Psychology, 17, 378396.

Markus, A. (2015). Mapping social cohesion: The Scanlon Foundation Surveys national report. Melbourne, Australia: Monash University. Retrieved from http://scanlonfoundation.org.au/wp-content/uploads/2015/ 10/2015-Mapping-Social-Cohesion-Report.pdf

Marr, D., \& Wilkinson, M. (2003). Dark victory. Sydney, Australia: Allen and Unwin.

Mathew, P., \& Harley, T. (2014). Refugee protection and regional cooperation in Southeast Asia. Canberra, Australia: Australian National University. Retrieved from https:/digitalcollections.anu.edu.au/bitstream/1885/11662/ 1/Mathew\%20\%26\%20Harley\%20Refugee\%20protection\% 202014.pdf

McKay, F.H., Thomas, S.L., \& Kneebone, S. (2012). 'It would be okay if they came through the proper channels': Community perceptions and attitudes toward asylum seekers in Australia. Journal of Refugee Studies, 25, 113-133.

Mitchell, G. (2015, September 28). When he came to Australia, he hadn't heard of the internet. Now this former refugee works for Google. Sydney Morning Herald. Retrieved from http://www.smh.com.au/nsw/when-he-came-to-australiahe-hadnt-heard-of-the-internet-now-this-former-refugeeworks-for-google-20150927-gjvt4k

Moloney, G. (2007). Social representations and the politically satirical cartoon: The construction and reproduction of the refugee and asylum-seeker identity. In G. Moloney \& I. Walker (Eds.), Social representations and identity: Content, process and power (pp. 61-84). New York, NY: Palgrave Macmillan.

Nickerson, R.S. (1998). Confirmation bias: A ubiquitous phenomenon in many guises. Review of General Psychology, 2, 175-220.

Otgaar, H., Smeets, T., \& Peters, M. (2012). Children's implanted false memories and additional script knowledge. Applied Cognitive Psychology, 26, 709-715.

Parliament of Australia. (2015). Asylum seekers and refugees: What are the facts? Canberra, Australia: Author. Retrieved from http://parlinfo.aph.gov.au/parlInfo/search/ display/display.w3p;query=Id\%3A\%22library\%2Fprspub\% 2FHGNW6\%22?utm_source=twitterfeed\&utm_medium = twitter

Paul, B., Salwen, M.B., \& Dupagne, M. (2000). The third-person effect: A meta-analysis of the perceptual hypothesis. Mass Communication \& Society, 3, 57-85.

Pedersen, A., Attwell, J., \& Heveli, D. (2005). Prediction of negative attitudes toward Australian asylum seekers: False beliefs, nationalism and self-esteem. Australian Journal of Psychology, $57,148-160$.

Pedersen, A., Beven, J., Walker, I., \& Griffiths, B. (2004). Attitudes toward Indigenous-Australians: The role of empathy and guilt. Journal of Community and Applied Social Psychology, 14, 233-249. DOI: 10.1002/casp.771

Pedersen, A., Clarke, S., Dudgeon, P., \& Griffiths, B. (2005). Attitudes toward Indigenous-Australians and asylum-seekers:
The role of false beliefs and other social-psychological variables. Australian Psychologist, 40, 170-178.

Pedersen, A., \& Hartley, L.K. (2015). Can we make a difference? Prejudice towards asylum seekers in Australia and the effectiveness of antiprejudice interventions. Journal of Pacific Rim Psychology, 9, 1-14.

Pedersen, A., Watt, S., \& Hansen, S. (2006). The role of false beliefs in the community's and the federal government's attitudes toward Australian asylum seekers. Australian Journal of Social Issues, 41, 105-124.

Penovic, T. (2016). Harsh treatment of asylum seekers breaches human rights. Melbourne, Australia: Monash University. Retrieved from http://www.monash. edu/_data/assets/pdf_file/0015/232602/human-rightsreport-2015.pdf

Perloff, R.M. (1993). Third-person effect research 1983-1992: A review and synthesis. International Journal of Public Opinion Research, 5, 167-184.

Pew Research Center. (2011). Press widely criticized, but trusted more than other information sources. Washington, DC: Author. Retrieved from http://www.peoplepress.org/2011/09/22/press-widely-criticized-but-trustedmore-than-other-institutions/

Potter, J. (1996). Representing reality: Discourse, rhetoric and social construction. London: Sage.

Putra, I.E. (2014). The role of ingroup and outgroup metaprejudice in predicting prejudice and identity undermining. Peace and Conflict: Journal of Peace Psychology, 20, 574.

Robinson, T., \& Umphrey, D. (2006). First-and third-person perceptions of images of older people in advertising: An inter-generational evaluation. The International Journal of Aging and Human Development, 62, 159-173.

Schacter, D.L. (2012). Adaptive constructive processes and the future of memory. American Psychologist, 67, 603.

Skurnik, I., Yoon, C., Park, D.C., \& Schwarz, N. (2005). How warnings about false claims become recommendations. Journal of Consumer Research, 31, 713-724.

Steele, Z., Silove, D., Brooks, R., Momartin, S., Alzuhairi, B., \& Susljik, I. (2004). Impact of immigration detention and temporary protection on the mental health of refugees. British Journal of Psychiatry, 188, 58-64

Suhnan, A., Pedersen, A., \& Hartley, L.K. (2012). Re-examining prejudice against asylum seekers in Australia: The role of people smugglers, the perception of threat, and acceptance of false beliefs. The Australian Community Psychologist, 24, 79-97.

Sulaiman-Hill, C.M.R., Thompson, S.C., Afsar, R., \& Hodliffe, T.L. (2011). Changing images of refugees: A comparative analysis of Australian and New Zealand print media 19982008. Journal of Immigration and Refugee Studies, 9, 345366.

Sun, Y., Pan, Z., \& Shen, L. (2008). Understanding the thirdperson perception: Evidence from a meta-analysis. Journal of Communication, 58, 280-300.

Surawski, N., Pedersen, A., \& Briskman, L. (2008). Resisting refugee policy: Stress and coping of refugee advocates. The Australian Community Psychologist, 22, 16-29. 
Turoy-Smith, K., Kane, R., \& Pedersen, A. (2013). The willingness of a society to act on behalf of Indigenous Australians and refugees: The role of contact, intergroup anxiety, prejudice and support for legislative change. Journal of Applied Social Psychology, 43(Suppl. S2), E179E195.

United Nations Higher Commissioner for Refugees. (2013). War's human cost: UNCHR Global Trends Report 2013. Retrieved from http://www.unhcr.org/ 5399a14f9.html
Wood, R. (2017). Sales of Orwell's 1984 surge after Trump aide's 'alternative facts'. Nine News. Retrieved from http://www. 9news.com.au/world/2017/01/25/13/17/sales-of-orwellnovel-surge-after-conway-comment\#2tsRfxAeCfTlPbUd.99. http://www.9news.com.au/world/2017/01/25/13/17/salesof-orwell-novel-surge-after-conway-comment

Wright, S.C., Aron, A., McLaughlin-Volpe, T., \& Ropp, S.A. (1997). The extended contact effect: Knowledge of crossgroup friendships and prejudice. Interpersonal Relations and Group Processes, 73, 73-90. 